\title{
A Tracer Study for the Improvement of Hydrodynamic Properties of Anaerobic Baffled Reactors (ABRs)
}

\author{
S. Uyanik
}

\begin{abstract}
The optimum mixing pattern in anaerobic reactors is a subject of much debate. Under plug flow conditions incoming substrate remains in the reactor for one retention time, allowing maximum time for conversion. However, the high substrate concentrations resulting from lack of dispersion may inhibit bacterial activity. On the other hand, excessive dispersion may result in short -circuiting of substrate and would not be ideal for granule formation in some anaerobic reactor configurations. Excessive substrate feeding during start-up can lead to the accumulation of volatile fatty acids and a concomitant decrease in $\mathrm{pH}$ in anaerobic baffled reactors because of their plug flow characteristics. In addition, plug flow reactors fed with high strength wastewater are more likely to expose sensitive bacteria to toxic levels of inorganic and organic compounds at inlet area. To overcome these difficulties, substrate feeding pattern to the reactor could be manipulated. Such a configuration, the split fed anaerobic baffled reactor (SFABR), has been developed in the Environmental Engineering Laboratories of Newcastle University in 2001. During the development of this reactor, tracer study was used to decide split ratio of the reactor. As a result of the tracer study, it was concluded that a split ratio of $0.4,0.3,0.2$, and 0.1 should be ideal for the SFABR.
\end{abstract}

Index Terms-Anaerobic baffled reactor (ABR), mixing, split fed anaerobic baffled reactor (SFABR), tracer study.

\section{INTRODUCTION}

One of the high rate anaerobic reactor configurations with an ability to support a dynamic active population within the system is the anaerobic baffled reactor (ABR). The ABR manifests a number of advantages that make it one of the most stable anaerobic reactor configurations for wastewater treatment. These have been documented in a review by Barber and Stuckey [1].

Despite many inherent advantages, one potential problem that can be encountered with an ABR during the start-up period results from the near plug-flow characteristics of this configuration. The appearance of a substrate concentration gradient occurring in high rate anaerobic reactors has long been a problem for optimization of sludge bed systems [2]. In this context, the strength of the wastewater and organic loading rate are known to have an important role during the start-up period of any anaerobic reactor. Initial organic loading rates should be sufficiently low that the slow growing micro-organisms do not become overloaded. Excessive substrate feeding during start-up can cause the accumulation of volatile fatty acids and in turn a severe decrease in $\mathrm{pH}$. In

Manuscript received March 21, 2018; revised June 25, 2018.

S. Uyanik is with the Harran University, Turkey (e-mail: suyanik@harran.edu.tr). addition, a high strength wastewater is more likely to build up toxic levels of inorganic and organic compounds in the initial compartments [3]. To overcome these difficulties, a low OLR, dilution of the feed, and effluent recycling have been recommended. There have been several attempts at effluent recycling in ABRs in order to increase the efficiency, to alleviate the problems of low $\mathrm{pH}$ caused by high levels of volatile fatty acids at the front of the reactor, to dilute toxicants, to reduce substrate inhibition and discourage gelatinous bacterial growth at the reactor inlet [2]-[5]. However, it is believed that there are several disadvantages of recycling with regard to maintenance including the cost of recycling pumps, and excessive biomass washout. Besides, owing to its compartmentalized structure, these approaches may not be the best solution to the successful start-up of ABRs on account of the fact that whilst a low OLR may be suitable for the initial compartments of the ABR, the latter compartments would always be nutrient limited. Therefore, effluent recycle cannot be recommended as a panacea for start-up in ABRs. Another suggestion to prevent failure of the reactor as a result of the low $\mathrm{pH}$ in the initial compartments was to use chemical buffering of $\mathrm{pH}$ in the first compartment [6]. It has been demonstrated that the demand of sodium bicarbonate for $\mathrm{pH}$ maintenance in the ABR was two times greater than for either UASB or anaerobic filters [7]. This approach, of course, would incur an additional cost in the provision of the required alkalinity.

An optimized configuration of ABRs should be configured to eliminate the harsh conditions in the initial compartments of the reactor and provide sufficient substrate for the anaerobic bacteria in the final compartments of the reactor.

This was achieved by manipulation of the substrate feeding pattern to the reactor by the author in 2001 in Newcastle University [8]. Specifically, the feed was split (i.e. distributed to each compartment of the reactor) at ratios that reflected the relative rates of acidogenic and methanogenic processes for the wastewater. This new reactor configuration was named Split Fed Anaerobic Baffled Reactor (SFABR).

Methanogenic anaerobic digesters have an inherent degree of mixing from the continuous stream of methane bubbles that rise within the reactor, however this natural mixing is usually considered to be rate limiting for efficient mass transfer. Consequently, contact between the organic matter and the microorganisms should be improved by enhanced mixing, leading to higher reactor performance. The level and type of mixing also affects the growth rate and distribution of microorganisms within the sludge, substrate availability and utilization rates, granule formation, and gas production [9].

Mixing can be enhanced using;

1) mechanical devices (paddles, turbines and propellers), 
2) hydraulic shear force (feed recycle), and

3) gas recirculation.

Stafford [10] reported that as long as adequate mixing was achieved, the method of mixing had little bearing on the digestion rate. However, it was also reported that excessive mixing could actually lead to a reduction in reactor performance. McMahon et al. [11] reported that continuously mixing reactors can lead to inhibition of the syntrophic oxidation of volatile fatty acids, possibly by disrupting the spatial juxtaposition of syntrophic bacteria and their methanogenic partners.

Smith et al. [9] stated that although plug-flow conditions enable feed components to remain in the reactor for one complete hydraulic retention time (HRT), giving maximum theoretical contact time, the potentially high concentration of substrates and their fermentation products that can occur at the reactor inlet might inhibit the biomass. On the other hand, although excessive mixing alleviates this problem, it may result in short-circuiting of the reactor, leading to unconverted substrate appearing in the reactor effluent. In practice, an intermediate degree of mixing appears to give the best substrate conversion by striking a balance between these adverse effects. The relationship between performance and mixing can be quantified using spikes of lithium tracer in the reactor feed to indicate mixing efficiency [9].

\section{MATERIAL AND METHODS}

Two identical reactors (Fig. 1), having the dimensions, 20 $\mathrm{cm}$ wide, $60 \mathrm{~cm}$ long, $100 \mathrm{~cm}$ high, were constructed from perspex with the active reactor volume (100 l) being divided into four equal 251 compartments, each separated by a vertical baffle. Within each compartment, downcomer and riser regions were created by a further baffle. The width of the downcomer was $4 \mathrm{~cm}$, (associated wet volume of $6.67 \mathrm{l}$ ), and the riser was $11 \mathrm{~cm}$, (associated wet volume of $18.33 \mathrm{l}$ ). The lower parts of the downcomer baffles were angled at 45 degrees in order to direct the flow evenly through the riser. This produced effective distribution and contact between the wastewater and anaerobic sludge at the base of each riser. A simple siphon at the effluent line controlled the water level in the reactors.

Each compartment was equipped with sampling ports that allowed biological solids, gas, and liquid samples to be withdrawn. In addition, the sidewalls were enclosed within a water-jacket to maintain the reactor temperature at $35^{\circ} \mathrm{C}$.

It was known from the literature that the Normal Fed Anaerobic Baffled Reactor (ABR) showed potential limitations during the start-up period from adverse $\mathrm{pH}$ and high concentrations of volatile fatty acids arising in the initial compartments as a result of the near plug flow characteristics of this reactor configuration.

Consequently, a new configuration of $\mathrm{ABR}$ was required to improve reactor reliability during the start-up period lessening the stress from organic load in the initial compartments whilst providing adequate substrate for bacteria in the final compartment. It was believed that increased mixing could eliminate most of the problems. In order to increase mixing in the ABR, the feed was split at a ratio, which was decided by a tracer study.

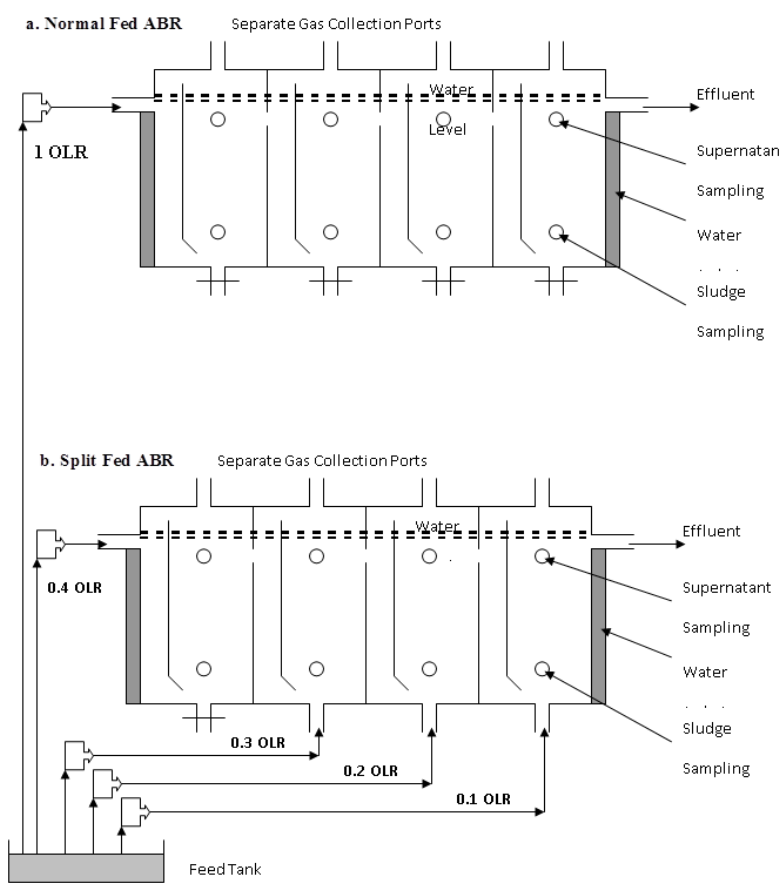

Fig. 1. Schematic diagram of a normal fed anaerobic baffled reactor (NFABR) and a split fed anaerobic baffled reactor (SFABR) showing an example of the split feed ratio as a fraction of the total OLR.

\section{TRACER STUDY}

In order to determine the mixing characteristics in the normal fed ABR and SFABR and to identify an efficient split ratio, tracer studies were carried out before seeding the reactors. This involved a pulse input of lithium chloride $(1 \mathrm{~L}$, $450 \mathrm{mg} / \mathrm{l})$ being added to the reactor under continuous flow conditions over a two minutes period. Then, 30 minutes after completing this pulse, $\mathrm{Li}+$ concentrations were measured in the reactor effluent at 30 minutes intervals for approximately 3 HRT (6 days) by atomic absorption spectrometry [12] and results plotted after normalizing values in accordance with the methods of [13]. Experimental set up for the tracer study can be seen in Fig. 2.

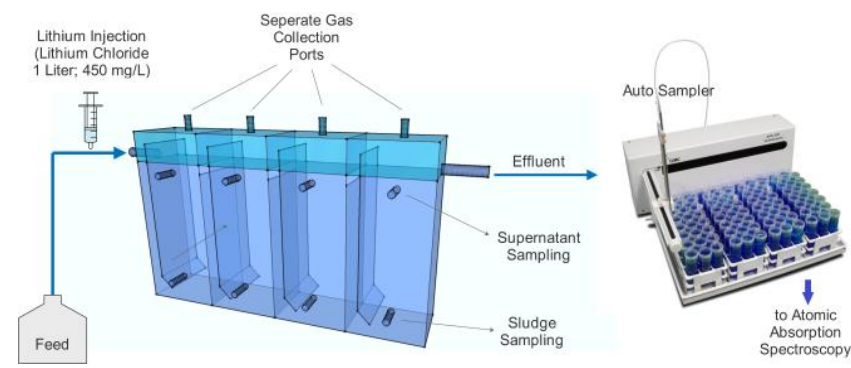

Fig. 2. Experimental set-up for tracer study.

\section{RESUlTS AND DISCUSSION}

The mainly used anaerobic reactors are the mixed batch, the plug-flow, the packed bed, the up-flow anaerobic sludge blanket (UASB), the fluidized bed type reactors and the continuously stirred tank reactors. They all have advantages and disadvantages for the effective treatment of organic matters. In the literature, they are all called as ideal reactors. Unfortunately, in the real world we often observe behavior very different from that expected. 
In an ideal plug-flow reactor, the substrate remains inside the reactor for exactly the same amount of time. Similarly, in an ideal batch reactor, all the substrate within the reactor have been inside it for an identical length of time. For the CSTR; the feed introduced into a CSTR at any given time becomes completely mixed with the material already in the reactor. In other words, some of substrate entering the CSTR leave it almost immediately because material is being continuously withdrawn from the reactor; other substrate remains in the reactor almost forever because all the material is never removed from the reactor at one time. These situations can be advantage or disadvantage for any given reactor or substrate. We, scientists, try to increase the performance of the reactor types for our purposes.

An economical and optimized solution to produce a more stable ABR during a short start-up period might be to eliminate the harsh conditions in the initial compartments of the reactor and provide sufficient substrate for the anaerobic bacteria in the final compartments of the reactor. This could be achieved by manipulation of the substrate-feeding pattern within the reactor. Such a configuration, the Split Fed Anaerobic Baffled Reactor (SFABR), has been developed. The concept is based on a modified feeding strategy for the ABR. Conventional ABRs are fed via a single inlet in the first compartment after which the wastewater flows to the outlet alternately over and under staggered vertical baffles [14]. However, in the SFABR, the feed is split and distributed to each compartment of the reactor at ratios that can be selected on the basis of the relative rates of acetogenic and methanogenic processes for the particular wastewater configuration. By splitting the feed, a number of desirable characteristics can be encouraged, such as low organic loading rate (OLR), longer hydraulic retention time (HRT), longer cell retention time in the initial compartments and greater availability of food for the microorganisms in the final compartment of the reactor. In addition, it is envisaged that a greater stability of $\mathrm{pH}$ should occur as a result of the lower concentrations of Volatile Fatty Acids arising in the initial reactor compartments. These factors are likely to lower organic stress in the initial compartments and encourage a more balanced microbial ecology in all compartments. Furthermore, gas production by methanogenesis is encouraged in the initial and final compartments relative to the Normal Fed Anaerobic Baffled Reactor. This will promote better gas mixing in the reactor as a whole, leading to more efficient substrate conversion.

Trace analysis experiments were performed in empty reactors to investigate the effect of input splitting on mixing patterns and determine the split ratio that would be used in the subsequent experiments. The optimum mixing pattern is a subject of much debate. Under plug flow conditions incoming substrate remains in the reactor for one retention time, allowing maximum time for conversion. However, the high substrate concentrations resulting from lack of dispersion may inhibit bacterial activity. On the other hand, excessive dispersion may result in short -circuiting of substrate and would not be ideal for granule formation in some anaerobic reactor configurations. Consequently, an intermediate degree of mixing appears to be optimal for substrate conversion [9].

Grobicki [6] studied the mixing pattern in ABRs and observed that with no biomass in the reactors, the system approximated to plug flow conditions. In this study the Ccurve (normalized concentration vs. normalized time; [13]) of the NFABR (Fig. 3) produced a pattern similar to that identified by Grobicki [6]. However, when the split fed regime was applied, the pattern changed corresponding to a better mixing pattern in the reactor. The two split ratio regimes (the fraction of load each compartment received) examined in this study were $0.6,0.25,0.1,0.05$ and $0.4,0.3$, $0.2,0.1$ of which the latter ratio produced a mixing pattern which may be considered as an ideal intermediate between plug flow and completely mixed reactors.

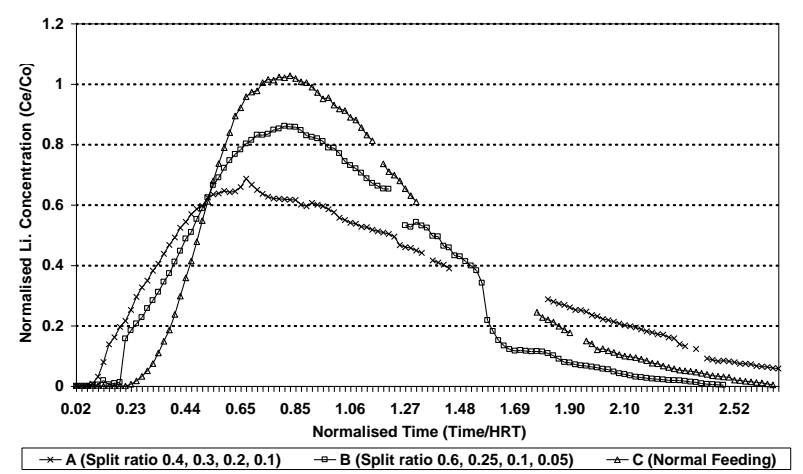

Fig. 3. C Curves for selected split ratios.

\section{CONCLUSION}

The results of tracer study curves showed that splitting feed into ABR had influence on the hydraulic characteristics of the reactor. So the utilization of the SFABR can increase mixing in the four compartment reactor and the reactor tends to have completely-mixed pattern rather than plug flow pattern of normal fed ABR. Feeding ratio of 0.6, 0.25, 0.1, 0.05 created a mixing tends to completely mixed pattern. Feeding ratio of 4:3:2:1 gives a result tends to intermediate degree of mixing, which could be assumed to be ideal for high rate ABR.

\section{REFERENCES}

[1] W. P. Barber and D. C. Stuckey, "The use of the anaerobic baffled reactor (ABR) for wastewater treatment: A review," Water Research, vol. 33, pp. 1559-1578, 1999.

[2] J. B. Lier, A. Tilche, B. K. Ahring, H. Macarie, R. Moletta, M. Dohanyas, L. W. H. Pol, P. Lens, and W. Verstraete, "New perspectives in anaerobic digestion," Water Science and Technology, vol. 43, no. 1, pp. 1-18, 2001.

[3] Y. Z. Dai, H. C. Shi, and Y. Qian, "An anaerobic baffled reactor for pentachlorophenol degradation," Journal of Environmental Science and Health Part A, vol. 35, pp 1803-1810, 2000.

[4] A. Bachmann, V. L. Beard, and P. L. McCarty, "Comparison of fixed-film reactors with a modified sludge blanket reactor," in Proc. the 1st. International Conference on Fixed Film Biological Processes, Noyes Date Corporation, pp. 1192-1211, 1983.

[5] A. Bachmann, V. L. Beard, and P. L. McCarty, "Performance characteristics of the anaerobic baffled reactor," Water Research, vol. 19, pp. 99-106, 1985.

[6] A. Grobicki, "Hydrodynamic characteristics and performance of the anaerobic baffled reactor," $\mathrm{PhD}$ thesis, Imperial College of Science, Technology and Medicine, London, 1989.

[7] M. Hutnan, M. Drtil, L. Mrafkova, J. Derco, and J. Buday, "Comparison of start-up and anaerobic wastewater treatment in UASB, hybrid, and baffled reactor," Bioprocess Engineering, vol. 21, pp. 439-445, 1999.

[8] S. Uyanik, "A novel anaerobic reactor: Split fed anaerobic baffled reactor (SFABR)," Turkish J. Eng. Env. Sci., vol. 27, pp. 339-345, 2003. 
[9] L. C. Smith, D. J. Elliot, and A. James, "Mixing in upflow anaerobic filters and its influence on performance and scale-up," Water Research vol. 30, pp. 3061-3073, 1996.

[10] D. A. Stafford, "The effects of mixing and volatile fatty acid concentration on anaerobic digester performance," Trib. Cebedeau, vol. 34, no. 456, pp. 493-500, 1981.

[11] K. D. McMahon, P. G. Stroot, R. I. Mackie, and L. Raskin, "Anaerobic codigestion of municipal; solid waste and biosolids under various conditions- I. Microbial population dynamics," Water Research, vol. 35, pp. 1817-1827, 2001

[12] APHA (American Public Health Association), Standard Methods for Examination of Water and Wastewater, $16^{\text {th }}$. Edition. Washington, DC, 1985.

[13] O. Levenspiel, Chemical Reaction Engineering, $1^{\text {st }}$ Edition. New York, John Wiley and Sons, 1962.

[14] A. Grobicki and D. C. Stuckey, "Performance of the anaerobic baffled reactor under steady- state and shock loading conditions," Biotechnology and Bioengineering, vol. 37, pp. 344-355, 1991.

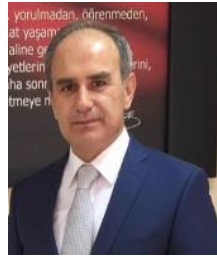

Sinan Uyanik was born in 1972 in Turkey. He is an environmental engineer. He has gained his BSc degree from Dokuz Eylul University, İzmir. He studied at the University of Newcastle upon Tyne and got his MSc and $\mathrm{PhD}$ degrees in Environmental Engineer Department from this prestigious institution. His $\mathrm{PhD}$ was about anaerobic digestion and completed under the supervision of Prof G.K. Anderson. During his PhD, a novel anaerobic reactor, split fed anaerobic baffled reactor was developed. $\mathrm{He}$ has done post graduate study in Cornell University, USA in 2007.

After completing post graduate studies, he was returned to his country, Turkey in 2001. He was appointed as a lecturer in one of the newly founded university, Harran University. He has been working at Harran University since then. He has been teaching environmental engineering department students and supervised over more than $20 \mathrm{MSc}$ and PhD students. He is a co- author of Anaerobic Treatment Processes chapter in the Handbook of water and wastewater microbiology book. His research interests are wastewater treatment, anaerobic digestion, acidic mine drainage water, EU water framework directive and renewable energy sources, especially energy from biomass.

Prof. Dr. Sinan Uyanik has published over 50 national and international papers about wastewater treatment. 